\title{
HDFx: A Novel Biologic Immuno Modulator for potential Control and Treatment of NK Cell and Macrophage Dysfunction in Drug-Resistant Tuberculosis
}

\author{
Burton M Altura ${ }^{1-6 \star}$ and Bella T Altura ${ }^{1,3-6}$ \\ ${ }^{1}$ Professor, Department of Physiology and Pharmacology, State University of New York Downstate Medical Center, USA \\ ${ }^{2}$ Professor, Department of Medicine, State University of New York Downstate Medical Center \\ ${ }^{3}$ Professor, The Center for Cardiovascular and Muscle Research, USA \\ ${ }^{4}$ Professor, The School of Graduate Studies in Molecular and Cellular Science, State University of New York, Downstate Medical Center, \\ Brooklyn, New York, USA \\ ${ }^{5}$ Professor, Bio-Defense Systems, Rockville Centre, New York, USA \\ ${ }^{6}$ Professor, Orient Biomedica, Estero, Florida, USA
}

\section{Article Info}

\section{*Corresponding author: Burton M Altura}

Professor

Department of Physiology \& Pharmacology State University of New York Downstate Medical Center

Brooklyn, New York

USA

Tel: 718-270-2194

E-mail: baltura@downstate.edu

Received: May 28, 2017

Accepted: June 22, 2017

Published: June 27, 2017

Citation: Altura BM, Altura BT. HDFx: A Novel Biologic Immuno Modulator for Potential Control and Treatment of NK Cell and Macrophage Dysfunction in DrugResistant Tuberculosis. Madridge J Immunol. 2017: 1(1): 13-15.

doi: $10.18689 / \mathrm{mjim}-1000104$

Copyright: (c) 2017 The Author(s). This work is licensed under a Creative Commons Attribution 4.0 International License, which permits unrestricted use, distribution, and reproduction in any medium, provided the original work is properly cited.

Published by Madridge Publishers
It has been suggested that "in the first two decades of the twenty-first century one billion people will become infected with tuberculosis" [1]. McMillen suggests that of these, "two hundred million will live with an active disease [1]". Although Robert Koch discovered the cause of tuberculosis (TB; Mycobacterium tuberculosis), micro scopically, in 1882, using an acid-fast stain [2]. A vaccine has been developed and in use for approximately 100 years, and a number of drugs (e.g., antibiotics) have been in use for more than six decades [1,2]. However, approximately 1.5-2 million people die worldwide of complications of TB per year [3]. Many of these complications involve opportunistic infections like HIV/AIDS as well as invasion of the lungs with Candida/ Aspergillus fungi [4-6]. A great many of these deaths appear to be due to a drugresistant TB crisis [1-3].

TB causes major dysfunction of different arms of the innate immune system, particularly alveolar macrophages and natural killer (NK) cells $[3,7]$. The NK cells together with the macrophages contribute vey significantly to a host's ability to inhibit and keep-check on the growth of M.tuberculosis $[3,7,8]$. Macrophages are, in many respects, like amoeba; they engulf particulate matter, e.g., bacteria. The immunocompetent macrophages ingest, digest, and degrade microorganisms, in general, including M.tuberculosis. The NK cells produce a variety of molecules which can prime macrophages like interferon-gamma (INF-gamma) [7,8]. When macrophages are hyperactivated, they produce a variety of molecules such as tumor necrosis factor-alpha (TNF), which then begin to produce interleukins, particularly IL12 which exert direct stimulatory actions on NK cells, which in turn will induce more IL-12 secretion from the latter NK cells $[7,8]$. NK cells produce a variety of cytotoxic agents such as IL-2, INF-gamma, perforin, granzymes, and granulysin, among other molecules [7-10]. Release of INF-gamma from these NK cells cause /trigger a variety of mechanisms within the macrophages, i.e., activation of NADPH-oxidase types 1 and 2 , as well as several types of reactive oxygen and nitrogen species, and receptor-interacting-threonine kinases 1 and 3(RIP1-RIP3) which promote programmed necrosis $[3,10]$. Normally, NK cells do not produce IL-12, but do so with 
infections $[9,10]$. So, both macrophages and NK cells work, normally, to stem infections. However, in cases of TB, both cell types "bite-off- more than they, literally, can chew-up" [9]. Once the TB mycobacteriums get inside the alveolar macrophages, in the lung, they multiply and burst out of the macrophages and infect other alveolar macrophages despite some weakened stimulation from the NK cells. M. tuberculosis bacilli cell walls have the capability to prevent fusion of alveolar phagosomes with the lysosomes (which normally contain a number of antibcterials), thus often protecting the bacilli from being digested and killed. When the alveolar macrophages die by necrosis, this pathologic phenomenon damages the lungs and initiate inflammatory reactions, thus recruiting other immune cells to the tissuedamaged lung sites, and causing further tissue and cell damage. During these inflammatory stages, multiple cytokines (above) are released promoting further lungtissue damage in a never-ending pathological cycle, leading to bleeding and death of the host. In view of this pathological cycle, and its dependence on loss and damage of macrophages and NK cells, it would appear that a proper therapeutic, and preventive, approach to drugresistant $T B$, would be to stimulate new macrophages and NK cells with increased immunocompetence.

By about 2075, the number of people dying from drugresistant infections (including that from $T B$ ) could reach in excess of 35 million per year. Added to this is the evergrowing and soaring worldwide use of antibiotics in agriculture. How much of this indiscriminate use of antibiotics is contributing to the ever-growing resistance of pathogens, like TB, to the antibiotic over-use is not known.

Our laboratories have been working on a new approach to develop host-defense factors that stimulate various arms of the innate and adaptive immune systems. To this end, we have discovered a new host-defense factor, termed "HDFx", that is a conserved protein found, so far, in mice, rats, guinea-pigs, rabbits, dogs and sub-human primates [12-19]. We assume it is also present in humans since it is a conserved molecule. More than 135 years ago, Elie Metchnikoff, the great father of immunology, hypothesized that the body, under stressful conditions, might produce powerful immune-stimulants which perforce would act on different arms of the innate immune system and serve to protect against major injuries and diseases [20]. Metchnikoff's early studies pointed to the important contributions of macrophages and phagocytic leukocytes to natural (innate) resistance against pathogenic bacteria and viruses. Over the past 30-40 years, considerable evidence has accumulated to support a strong relationship between the functional (physiological) state of the microcirculation, macrophages-phagocytes, NK cells, the reticuloendothelial system, and "pit cells" in the liver to host defense and resistance to pathogens, trauma, circulatory shock and combined injuries [3,7-10,21-29].

Recent studies from our laboratories have clearly shown that HDFx is protective (to different degrees) against a variety of systemic bodily insults ranging from hemorrhage, trauma, endotoxins, a variety of lethal bacteria (e.g., E.coli, S. enteritidis, C. welchii) to fungi such as candida, aspergillus, and fumagatus microorganisms [21-29], unpublished findings]. HDFx is a conserved $35-40 \mathrm{kD}$ protein found in a variety of mammals including sub-human primates [21-29], unpublished findings]. A unique attribute of HDFx is that it accelerates tissue-wound healing [23]. Most importantly, HDFx has been shown to inhibit the release of multiple cytokines and chemokines, from macrophages and lymphocytes, including TNF-alpha, IL-6, IL-8, IL-1 beta, IFNgamma, and IL-12 as well as several macrophage factors, in animals subjected to inflammatory conditions, circulatory shock, ischemia, endotoxin release, bacterial invasions, hemorrhage, and trauma [21], [24-29], unpublished findings]. In other words, HDFx clearly can either prevent or ameliorate the intensity of "cytokine storms" under a variety of conditions which normally produce intense inflammatory responses, severe tissue injury, and bleeding, events that eventually compromise and kill the host from TB invasion [16-18], [21]. We also produced preliminary data to suggest that HDFx might be useful in the treatment and amelioration of hemorrhagic fevers [16].

"Superbugs", like TB (as seen in HIV infections in patients), seem to be major culprits in many hospitalized patients. Many of the major antibiotics usually administered to TB and HIV patients either are not effective or have very diminished effectiveness $[1-3,8]$. In order to kill most bacteria, particularly the TB bacterium, most of the approaches towards treatment have been to design antibiotics which can penetrate the $M$. tuberculosis, macrophage and NK cell membranes, but most importantly the "waxy" coating on the TB bacterial membranes (due to mycolic acid) of the TB bacteria, is a very, very difficult task. In our opinion, another likely approach would be to engulf increased amounts of bacteria and accelerate the digestive processes within the "supercharged" macrophages and NK cells. HDFx appears, at least experimentally, to induce a "supercharged effect" [21-29]. But for this to occur in an expeditious manner, microcirculatory blood flows in the lung circulatory tree must perforce produce optimal or increased flow and distribution within the lung tissues. Therefore, an ideal drug or therapeutic molecule would be one that could stimulate multiple arms of the innate immune system coupled to modulation of microcirculatory blood flows to the aforementioned key organ tissues and cells. So far, of all molecules, we have investigated, HDFx appears to be the only molecule that embodies all these qualities and demonstrates therapeutic attributes against several "superbugs".

In conclusion, we believe that the approaches outlined in the above, using HDFx or its derivatives, could be the ideal drug(s) to pretreat all TB-antibiotic resistant patients and HIV patients who would be susceptible to invasion by TB bacteria. 


\section{Acknowledgements}

Some of the original studies and thoughts needed for the discovery of HDFx, and reviewed above, were initiated while the authors were at New York University School of Medicine and The Albert Einstein College of Medicine of Yeshiva University. Some of the original studies referred to, herein, were supported, in part, by unrestricted research grants from several pharmaceutical companies (Sandoz Pharmaceuticals, The UpJohn Co, CIBA-Geigy Pharmaceuticals, and Bayer Pharmaceuticals) as well as anonymous donors. We also were supported, in part, by Research Grants from The N.I.H.L.B.I. The authors are indebted to many colleagues, who worked very hard, over many years (i.e. C.Thaw, A. Gebrewold, A. Carella, R.W. Burton, and C. Parillo) to help bring our work to fruition.

\section{References}

1. Millen MC. CW Discovering Tuberculosis. Yale University Press, New Haven. 2015.

2. Cambau C, Drancourt M. Steps toward the discovery of Mycobacterium tuberculosis by Robert Koch. Clin Microbiol Infect. 2014; 20: 196-201. doi: 10.1111/1469-0691.12555

3. Allen $M$, Bailey $C$, Cahatol I, dodge L, Yim L, Kassissa $C$, et al. Mechanisms of control of Mycobacterium tuberculosis by NK cells: role of glutathione. Frontiers Immunol. 2015; 6: 508. doi: 10.3389/ fimmu.2015.00508

4. Toossi Z. Virological and immunological impact of tuberculosis on human immunodeficiency virus type 1 disease. J Infect Dis. 2003; 188: 1146-155. doi: 10.1086/378676

5. Corbett EL, Watt $\mathrm{Cl}$, Walker N, Maher D, Williams BG, Raviglione MC, et al. The growing burdens of tuberculosis: global trends and interactions with the HIV epidemic. Arch Int Med. 2003; 164: 1009-1021. doi: 10.1001/archinte.163.9.1009

6. Havlir DV, Getahun H, Sanne I, Nunn P. Opportunities and challenges for HIV care in overlapping HIV and TB epidemics. Jama. 2008; 300(4): 423-30. doi: 10.1001/jama.300.4.423

7. Guerra C, Johal K, Morris D, Moreno S, Alvarado O, Gray D, et al. Control of Mycobacterium tuberculosis growth by activated natural killer cells. Clin Exp Immunol. 2012; 4: 98. doi: 10.1111/j.1365-2249.2011.04552.x

8. Esin S, Batoni G. Natural killer cells; a coherent model for their functional role inMycobacterium tuberculosis infection. J Innate Immunol. 2015; 7(1): 11-24. doi: 10.1159/000363321

9. Kumar V, Delovitch TL. Different subsets of natural killer $T$ cells may vary in their roles in health and disease. Immunology. 2014; 142: 321336. doi: 10.1111/imm. 12247

10. Sompayrac L. How the Immune System Works. Wiley Blackwell, Oxford. 2016.

11. Beltz LA. Emerging Infectious Diseases. A Guide to Diseases, Causative Agents, and Surveillance. Josey-Bass, San Francisco. 2011.

12. Altura BM, Gebrewold A, Carella A. A novel immune modulator, HDFx, protects against lethal hemorrhage, endotoxins and intestinal ischemic shock: potential relevance to emerging diseases. Int $j$ Clin Exp Med. 2009; 2(3): 266-279.
13. Altura BM, Gebrewold A, Carella A. HDFx: a novel immunomodulator is therapeutically-effective in hemorrhagic and intestinal ischemic shock: importance of microcirculatoty-immunological interactions and their implications for the warfighter and disaster victims. Int J Clin Exp Med. 2011; 4(4): 331-40.

14. Altura BM, Carella A, Gebrewold A. HDFx: a novel biologic immunomodulator accelerates wound healing and it is suggestive of unique regenerative powers: potential implications for the warfighter and disaster victims. Int J Clin Exp Med. 2012; 5(4): 289-295.

15. Altura BM. A novel immune modulator and potential superbug superwarrior for hospitalized patients and battlefield casualties. Int J Vaccines \& Res. 2016; 3: 1-3.

16. Altura BM, Gebrewold A, Carella A. HDFx: A recently discovered biologic and its potential use in prevention and treatment of hemorrhagic fever viruses and antibiotic-resistant superbugs. I Haematol Thromboembolic Dis. 2016; 4: 252. doi: 10.4172/2329-8790.1000252

17. Altura BM. HDFx: A novel immune modulator for the amelioration of hypovolemic shock in the OR, cancer patients and on the battlefield. $J$ Clin Med therap. 2016; 1(1): e003.

18. Altura BM, Gebrewold A, Carella A, Altura BT. HDFx; A novel immunomodulator and potential fighter against cytokine storms in inflammatory and septic conditions in dogs and farm animals. Int J Vet Health Sci Res. 2017; 5(2e): 1-3.

19. Altura BM, Gebrewold A, Carella A, Altura BT. HDFx: A novel biologic immune modulator may have the potential to prevent bacteria in space from becoming aggressively infectious and lethal. Clin Res and Trials. 2017; 3(3): 1-3.

20. Metchnikoff E. Untersuchung ueber die intracellular Verdauung beiwirbellosen Thieren. Arbeiten aus dem Zoologischesen. Institut Wien. 1884; 5(2): 141-168.

21. Altura BM, Hershey SG. RES phagocytic function in trauma and adaptation to experimental shock. Am J Physiol. 1968; 215: 1414-19.

22. Hershey SG, Altura BM. Function of the reticulo endothelial system in experimental shock and combined injury. Anesthesiology. 1969; 30(2): 138-143.

23. Altura BM, Hershey SG. Effects of glycerol trioleate on the reticuloendothelial system and survival after experimental shock. $J$ Pharmacol Exp Ther. 1970; 175(3): 555-564.

24. Altura BM, Hershey SG. Sequential changes in reticuloendothelial function after acute hemorrhage. Proc Soc Exp Biol Med. 1972; 139(3): 935-39.

25. Altura BM. Hemorrhagic shock and reticulo endothelial system phagocytic function in pathogen-free animals. Circulatory Shock. 1974; 1: 295-300.

26. Altura BM, Gebrewold A. Prophylactic administration of antibiotics compromises reticuloendothelial system function and exacerbates shock mortality in rats. Br J Pharmacol. 1980; 68(1): 19-21.

27. Altura BM. Reticulo endothelial system function and histamine release in shock and trauma: relationship to microcirculation. Klin Wochenschr. 1982; 60(17): 1021-030.

28. Altura BM. Micro circulatory regulation and dysfunction: Relation to RES function and resistance to shock and trauma. The Reticuloendothelial System. 1985; 7: 353-395. doi: 10.1007/978-1-4613-2353-2_15

29. Altura BM. Endothelial and reticulo endothelial cell function: roles in injury and low-flow states. In: The Scientific Basis for the Care of the Critically ILL. Little RA, Frayn KN, eds. Manchester University Press, Manchester, The UK. 1986; 259-274. 